\title{
Modelling energy systems of Vietnam with integration of renewable power sources
}

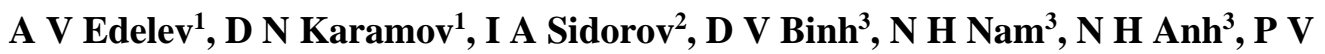 \\ Duy $^{3}$ and P T Hanh ${ }^{3}$ \\ ${ }^{1}$ Melentiev Energy Systems Institute of Siberian Branch of SB RAS, Lermontov St. \\ 130, Irkutsk, Russia, 664033 \\ ${ }^{2}$ Matrosov Institute for System Dynamics and Control Theory of SB RAS, Lermontov \\ St. 134, Irkutsk, Russia, 664033 \\ ${ }^{3}$ Institute of Energy Science of VAST, Block A9, Hoang Quoc Viet Street, Cau Giay \\ District, Hanoi, Vietnam \\ flower@isem.sei.irk.ru
}

\begin{abstract}
The paper addresses the research of the large-scale penetration of renewable energy into the power system of Vietnam. The proposed approach presents the optimization of operational decisions in different power generation technologies as a Markov decision process. It uses a stochastic base model that optimizes a deterministic lookahead model. The first model applies the stochastic search to optimize the operation of power sources. The second model captures hourly variations of renewable energy over a year. The approach helps to find the optimal generation configuration under different market conditions.
\end{abstract}

\section{Introduction}

Due to the rapid population growth and economic development, the Vietnamese government faced many issues while finding ways to satisfy future energy demands [1-3]. One of them is recent considerable growth of grid connected renewable energy (RE) [4-6]. In the period until 2030, Vietnam will prioritize the development of onshore wind farms while deploying solar power in areas without access to the power grid. Also, the Vietnamese government has introduced a number of incentives such as two-way meters, preferential import tariffs. It support to the local production of RE technologies and equipment, and the development of RE markets and Power Purchase Agreement policies [7].

Renewable energy (RE) sources have some advantages for the economy of Vietnam. First, RE can increase the diversity of energy supplies, and thus enhance the energy supply security. In this context, energy supply in Vietnam is increasingly dependent on coal and imported fuels. The energy imports will account for $37.5 \%$ of the energy mix in 2025, and 58.5\% in 2035 [7]. Therefore, the current and future energy security status of Vietnam might not be guaranteed. Second, higher RE integration might further reduce country's greenhouse gas emissions [8].

However, successful and cost-effective integration of RE into power grids has been challenged in reality. The capturing the economic and technical challenges related to RE large-scale penetration requires analysis of power mix taking into account access to the fuel and technical constraints on the power system operation as well as ensuring energy supply security and power system reliability [7, 9]. One of the emerging challenges is handling the high RE variability which might expose operational problems for traditional thermal plants by necessitating frequent cycling, including ramping and startup/shutdown [10].

Copyright (C) 2019 for this paper by its authors. Use permitted under Creative Commons License Attribution 4.0 International (CC BY 4.0). 


\section{Generation expansion planning}

The planning models are the traditional tool to analyse future developments in the energy sector. The capacity planning problem in the power systems has been divided into demand forecasting, distribution expansion planning, transmission expansion planning, and generation expansion planning (GEP). For each capacity planning problem, the time horizon can be divided into long-term, mediumterm, or short-term studies [11]. Short-term planning is associated with day-to-day system operation. Medium-term planning involves the maintenance of system assets. Long-term planning relates to new capacity additions [12].

GEP is a power plant mix problem that identifies types, location, and construction time of new generation technologies, which should be added to the existing system in order to meet the power demand over a specific planning horizon $[11,13]$. The contemporary, systematic, and robust GEP should consider [14]:

- Integration of electric vehicles in power systems [15],

- Integration of short-term operational aspects into decision making [16, 17],

- Power and fossil fuel systems interdependence,

- Energy storage and demand-side impacts on GEP,

- Policy implications on power investments, highlighting the role of supply of security.

The GEP models can be classified according to time horizon (static and dynamic), handling of uncertainties (deterministic and stochastic), network topology (the single-node or centralised and network constrained), and market structure (regulated and deregulated) [11].

From the other side, system planning models used in the power sector can be broadly categorized into the energy system and power system models, depending on their focus and application area [12]. While the first group of system planning models considers broader questions related to national or global energy policy [15], the second group focuses on regional or national power systems [18].

The GEP is usually an optimisation problem in which the aim is to distinguish the optimal size, type of generation unit, and commitment time of new generating facilities so as to satisfy the power demand at least cost over a planning horizon [11]. The goal is either to minimise or maximise a singleor multiple-objective functions subject to some constraints

$$
\begin{gathered}
\operatorname{extr} F(z)=\left[f_{1}(z), \ldots, f_{L}(z)\right], \\
\text { s.t. } \quad h_{n}(z)=0 ; n \in M_{h}, \\
g_{m}(z) \leq 0 ; m \in M_{g}, \\
z \in Z,
\end{gathered}
$$

where extr is minimization or maximization operation, $F$ is the objective vector, $f_{l}(z)$ is the $l$-th objective function, $l=1 \ldots L, z$ is decision vector belonging to the feasible solution space $Z, g_{m}(z)$ is the $m$-th inequality constraint, $h_{n}(z)$ is the $n$-th equality constraint, $M_{h}$ and $M_{g}$ are the numbers of equality and inequality constraints respectively.

The single-objective GEP model combines various objectives into one. This approach does not allow decision-makers to evaluate solutions that present trade-off among various objectives. The following works [19-21] presented the GEP as a single-objective optimisation problem.

The multi-objective generation expansion planning (MGEP) model can found a compromise among various capacity planning objective functions to obtain an optimal alternative [22].

\section{Generation expansion planning with high share of renewable energy}

The RE resources create for the power systems' operation some operational challenges for GEP due to the following feature of their stochastic nature [23-26]: 
- RE variability requires flexible generation that can ramp up and down quickly,

- The intermittency makes the output from RE sources uncertain.

- Power quality and voltage stability issues connected with RE variability that needs to be assessed, controlled, observed and mitigated appropriately,

These three aspects (variability, intermittency, and grid stability issues) necessitate a paradigm change in GEP models that assess the impact of increased penetration of RE [27-29]. Traditional GEP models have mostly focused on the conventional power plant whose operation and planning can be easily conducted by varying fuel inputs to match variability on the load side $[11,30]$. To address the operational challenges the grid might require additional levels of reserves [31-33]. Another way to mitigate these challenges is the adoption of storage units [34-36].

There are a lot of works that have included the integration of RE sources in GEP problem [37-42].

\section{Decision-making in energy planning}

Most of the decisions to be made by energy sector decision-makers are fed by information which is usually subject to uncertainties [43]. There are different types of uncertainty: Gaussian noise, heavytailed distributions, bursts, rare events, temporal uncertainty, lagged information processes, and model uncertainty [44]. The combination of the uncertainty types with decisions that may be binary, discrete, continuous or categorical, scalar or vector creates a virtually unlimited range of problems [45].

The uncertain parameters in the GEP problem studies can be generally classified into two categories [46]:

- Technical parameters which can be divided into topological and operational,

- Economical parameters which affect the economical indices.

There are much uncertainty handling methods developed for dealing with uncertain parameters: stochastic, possibilistic, hybrid and etc. The main difference between them is a way they choose to describe the uncertainty of the model's inputs. And they are similar in the attempt to quantify the influence of inputs on model's outputs [46].

\section{Problem formulation}

Our approach for solving GEP problem is based on the stochastic optimization framework [45, 47] that divides decision-making into the following five components: states, actions, exogenous information, transition function and objective function. Similarly to [48, 49], the proposed approach presents the optimization of operational decisions in GEP as a Markov decision process. It uses a stochastic base model that optimizes a deterministic lookahead model. The first model applies the stochastic search to optimize the operation of power sources and the second model captures hourly variations of RE over a year.

The simplified structure of the energy sector of Vietnam is represented as a network $G=(N, A)$, where $N$ is the set of the nodes and $A$ is the set of arcs. The node $i \in N$ represents a point of demand and/or supply of energy, and the arc $(i, j) \in A$ is a transmission line.

A set of power generation technologies $O$ consists of two subsets: fossil fuel-fired facilities and RE sources. $R$ denotes the RE subset. The fossil fuels constitute the set $F . q \in O$ is a power generation technology and $k \in F$ is a fossil fuel. $T$ is the number of periods (hours) in the planning horizon where $t \in T$ is a time period.

\subsection{The base model}

The base model is intensively based on the work [50]. The additional objectives and constraints are adopted from studies [51-53].

The current state of the Vietnamese energy sector in the period $t$ may be represented as

$$
s_{t}=\left(d_{i t}, h_{i q t}, b_{k t}, o_{k t}, p_{t}\right), i \in N, q \in R, k \in F, t \in T
$$


where $d_{i t}$ is the load/demand (MW) at the node $i$ in the period $t, h_{i a t}$ is the corresponding hourly capacity factor for each RE technology $q$ in the node $i$ during the period $t, b_{k t}$ is the local production (kTOE) of the fuel $k$ in the period $t, o_{k t}$ is the cost $(\$ / \mathrm{kTOE})$ of the fuel $k$ import in the period $t, p_{t}=\left(d_{i t^{\prime}}, h_{i q t^{\prime}}, b_{k t^{\prime}}, o_{k t^{\prime}}\right)$ is forecast for $t^{\prime}>t$.

The decisions variables in the period $t$ may be represented as

$$
x_{t}=\left(g_{i q t}, x_{i j t}, v_{i t}\right) ; i \in N,(i, j) \in A, q \in O, k \in F, t \in T
$$

where $g_{i q t}$ is the generation amount (MW) of the technology $q$ at the node $i$ in the period $t ; x_{i j t}$ is the flow (MW) through the arc $(i, j)$ in the period $t$, and $v_{i t}$ is the unmet demand (MW) at the node $i$ in the period $t$.

The set of feasible decisions in the period $t$ is defined by the following constraints:

- Node power balance equation: the generation plus flow from other nodes is equal to the sum of demand, shortage and flow to other nodes at the node $i \in N$ in the period $t \in T$ :

$$
\sum_{(j, i) \in A} x_{j i t}-\sum_{(i, j) \in A} x_{i j t}+\sum_{q \in O} g_{i q t}=d_{i t}+v_{i t} .
$$

- Fossil fuels demand in the period $t$ : The fuel $k$ will be either imported or taken from local markets

$$
\sum_{i \in N} \sum_{q \in O} w_{q t} g_{i q t} \leq u_{k t}+b_{k t} ; k \in F, t \in T,
$$

where $w_{q t}$ is the consumption of fuel (kTOE/MW) for the technology $q$ in the period $t$.

- Power generation limit on each conventional technology $q$ in the node $i$ during the period $t$ :

$$
g_{\text {iqt }} \leq y_{\text {iqt }} ; i \in N, q \in O \backslash R, t \in T \text {. }
$$

where $y_{i q t}$ is the total capacity (MW) of the technology $q$ at the node $i$ in the period $t$.

- Power generation limit on each RE technology $q$ in the node $i$ during the period $t$ :

$$
g_{\text {iqt }} \leq h_{\text {iqt }} y_{\text {iqt }} ; i \in N, q \in R, t \in T .
$$

- Power transmission limit on each arc $(i, j)$ in the period $t$ :

$$
x_{i j t} \leq p_{i j t} ;(i, j) \in A, t \in T .
$$

- Power system reliability: to ensure that the available generation capacity of power system is adequate to meet the expected power demand, the available system capacity in each period $t$ should be between the defined upper and lower bounds as

$$
\begin{aligned}
& \sum_{i \in N} \sum_{q \in O} g_{i q t} \leq \sum_{i \in N} d_{i t}\left(1+r^{\max }\right), \\
& \sum_{i \in N} \sum_{q \in O} g_{i q t} \geq \sum_{i \in N} d_{i t}\left(1+r^{\mathrm{min}}\right),
\end{aligned}
$$

where $r^{\max }$ is the maximum peak reserve requirement $(\%), r^{\min }$ is the minimum peak reserve requirement (\%).

- RE share: to impose a minimum of power generated from RE technologies and to determine the RE sources penetration limits to preserve the power system stability the value of RE 
sources share in the total system generation at each period $t$ should be between the defined lower and upper bounds as

$$
\begin{aligned}
& \sum_{i \in N} \sum_{q \in R} g_{i q t} \geq a_{t}^{\min } \sum_{i \in N} \sum_{q \in O} g_{i q t}, \\
& \sum_{i \in N} \sum_{q \in R} g_{i q t} \leq a_{t}^{\max } \sum_{i \in N} \sum_{q \in O} g_{i q t},
\end{aligned}
$$

where $a_{t}^{\min }$ is the minimum share of RE sources (\%) in the total system generation in the period $t, a_{t}^{\max }$ is the maximum share of RE sources $(\%)$ in the total system generation during the period $t$.

- Energy supply security: to ensure technology variability the available system capacity of technology $q$ may not exceed the upper bound in each period $t$

$$
\sum_{i \in N} g_{i q t} \leq y_{q t}
$$

where $y_{a t}$ is the given maximum system capacity of the technology $q$ during the period $t$.

- Nonnegativity: no negative values are permitted for the decision variables

$$
g_{i q t}, x_{i j t}, u_{k t}, v_{i t} \geq 0
$$

where $i \in N, q \in O,(i, j) \in A, k \in F$, and $t \in T$.

The transition from the state $s_{t}$ to the successor state $s_{t+1}$ is determined by the function $s^{M}$

$$
s_{t+1}=s^{M}\left(s_{t}, x_{t}, w_{t+1}\right) ; t \in T,
$$

where $w_{t+1}$ is uncontrolled exogenous process defined as the random variables that capture the stochastic updating of wind, solar, demand and cost forecasts. The $w_{t}$ is modeled as changes of $d_{i t}$, $h_{i a t}, b_{k t}$, and $o_{k t}$.

The total cost of the energy sector functioning $s_{t}$ over the period $t$ consists of operation and transmission costs, environmental impact, imports of fuel, and unmet demand cost:

- Operational and transmission costs: this objective function is defined as the total present value sum of the operation and maintenance costs

$$
f_{1}(t)=\sum_{i \in N} \sum_{q \in O} q_{i q t} g_{i q t} .
$$

In this objective, $q_{i q t}$ is the operation and maintenance cost (\$/MW) of the technology $q$ at the node $i$ in the period $t$.

- Fossil fuel import: the goal is to minimize the total amount of fuel imports

$$
f_{3}(t)=\sum_{k \in F} o_{k t} u_{k t}
$$

- Unmet demand: the goal is to minimize the total power shortage

$$
f_{4}(t)=\sum_{i \in N} l_{t} v_{i t},
$$

where $l_{t}$ is the cost (\$/MW) of not satisfying the demand in the period $t$.

- Environmental impact: this objective minimizes the environmental impacts 


$$
f_{2}(t)=\sum_{i \in N} \sum_{q \in O} e_{q t} g_{i q t}
$$

where $e_{q t}$ is the amount (tons) of carbon dioxide emission $\mathrm{CO}_{2}$ per $\mathrm{MW}$ generated by the technology $q$ at the node $i$ during the period $t$. The emission of other pollutants can be also included.

The total cost over the period $t$ may defined as

$$
c\left(s_{t}, x_{t}\right)=\sum_{l=1}^{4} f_{l}(t)
$$

The policy $\pi$ represented by the function $x_{t}^{\pi}\left(s_{t}\right)$ makes hourly planning decisions and returns the feasible decision $x_{t}$ for any system state $s_{t}$. The overall goal of the stochastic base model is to find the best policy. Since $s_{t}$ is a random variable, the objective function would be written as the minimization of the expected sum of total cost over the entire time horizon $T$

$$
\min _{\pi \in \Pi} e^{\pi} \sum_{t \in T} c\left(s_{t}, x_{t}^{\pi}\left(s_{t}\right)\right)
$$

\subsection{The lookahead model}

The deterministic model is the policy $x_{t}^{L A}\left(s_{t} \mid \theta\right)$ with the lookahead horizon as the tunable parameter $\theta$ [49]. It determines the decisions by solving the optimization problem

$$
\arg \min _{x_{t}} \sum_{t^{\prime}=t}^{t+\theta} \sum_{l=1}^{4} f_{l}\left(t^{\prime}\right),
$$

where the set of feasible decisions $x_{t}$ is defined by constraints (5)-(25) for each $t^{\prime}$ with $t \leq t^{\prime}<t+\min (T-t, \theta)$.

The solving the lookahead model in (20) is not an optimal policy but it helps obtain robust behaviour by tuning $\theta$ using the base model.

The approach was implemented using the continuous integration methodology in the Orlando Tools framework [54]. The methodology and framework made it possible to organize a single workflow of developing and testing of the distributed application for solving the above-formulated problem. The experiments were organized on the basis of the Irkutsk Supercomputer Center of SB RAS [55].

\section{Conclusions}

The proposed approach presents the optimization of operational decisions in different power generation technologies as a Markov decision process. It uses a stochastic base model that optimizes a deterministic lookahead model. The first model applies the stochastic search to optimize the operation of power sources. The second model captures hourly variations of renewable energy over a year.

The approach helps to find the optimal generation configuration under different market conditions. Also, the approach takes into account the following types of constraints: flow balance constraints in the network with demand covering, power generation and transmission limit, availability of local fossil fuels production, system reliability requirements, maximum and minimum shares of RE resources, and energy supply security requirements.

\section{Acknowledgments}

The authors especially thank IES VAST for providing fund and creating favour in data collection during the implementation of the study. 
The work was supported in part by the Program of fundamental research of SB RAS, project no. III.17.5.1 (AAAA-A17-117030310451-0), and the Russian Foundation for Basic Research, projects no. 19-07-00097-a (reg. no. AAAA-A19-119062590002-7) and no. 18-51-06001 (reg. no. AAAAA18-118050490009-5). The development of a technology for integrating Grid and cloud computing was supported by the Presidium RAS, program no. 2, project "Methods and tools for solving hardsearch problems with supercomputers" (reg. no. AAAA-A18-118031590005-5).

\section{References}

[1] Toan P K, Bao N M and Dieu N H 2011 Energy supply, demand, and policy in Viet Nam, with future projections Energy Policy 39(11) 6814-6826

[2] Do T M and Sharma D 2011 Vietnam's energy sector: A review of current energy policies and strategies Energy Policy 39(10) 5770-5777

[3] Tang C F, Tan B W and Ozturk I 2016. Energy consumption and economic growth in Vietnam Renewable and Sustainable Energy Reviews 54 1506-1514

[4] Luong N D 2015 A critical review on energy efficiency and conservation policies and programs in Vietnam Renewable and Sustainable Energy Reviews 52 623-634

[5] Quirapas M A J R, Lin H, Abundo M L S, Brahim S and Santos D 2015 Ocean renewable energy in Southeast Asia: a review Renewable and Sustainable Energy Reviews 41 799-817

[6] Mamat R, Sani M S M and Sudhakar K 2019. Renewable energy in Southeast Asia: Policies and recommendations Science of The Total Environment 670 1095-1102

[7] Edelev A, Nguyen H N, Luu L Q 2018 Estimating Solar Power Integration into Vietnam's Power Mix with the Combinatorial Modelling Approach Vth Int. worksh. Critical infrastructures: Contingency management, Intelligent, Agent-based, Cloud computing and Cyber security (Atlantis Press)

[8] Edelev A V, Tchemezov A V, Nam N H and Binh D V 2013 Sustainable energy development and green growth strategy for Vietnam: a suitable pathway of power sector ensuring the national energy security Proc. of the 3 Int. Sci. Conf. Sustainable Energy Development pp. 21-28

[9] Wierzbowski M, Lyzwa W and Musial I. 2016 MILP model for long-term energy mix planning with consideration of power system reserves Applied Energy 169 93-111

[10] Vithayasrichareon P, Riesz J and MacGill I. 2017 Operational flexibility of future generation portfolios with high renewables Applied Energy 206 32-41

[11] Babatunde O M, Munda J L and Hamam Y 2019 A comprehensive state-of-the-art survey on power generation expansion planning with intermittent renewable energy source and energy storage Int. J. of Energy Res 1-30

[12] Das P, Mathur J, Bhakar R and Kanudia A 2018 Implications of short-term renewable energy resource intermittency in long-term power system planning Energy strategy reviews 22 1-15

[13] Sadeghi H, Rashidinejad M and Abdollahi A 2017 A comprehensive sequential review study through the generation expansion planning Renewable and Sustainable Energy Reviews 67 $1369-1394$

[14] Koltsaklis N E and Dagoumas A S 2018 State-of-the-art generation expansion planning: A review Applied energy 230 563-589

[15] Lopes J A P, Soares F J and Almeida P M R 2010 Integration of electric vehicles in the electric power system Proceedings of the IEEE 99(1) 168-183

[16] Deane J P, Chiodi A, Gargiulo M and Gallachóir B P Ó 2012 Soft-linking of a power systems model to an energy systems model Energy 42(1) 303-312

[17] Collins S, Deane J P, Poncelet K, Panos E, Pietzcker R C, Delarue E and Gallachóir B P Ó 2017 Integrating short term variations of the power system into integrated energy system models: A methodological review Renewable and Sustainable Energy Reviews 76 839-856

[18] Gargiulo M and Gallachóir B Ó 2013 Long term energy models: Principles characteristics focus and limitations Wiley Interdisciplinary Reviews: Energy and Environment 2(2) 158-177

[19] Connolly D, Lund H, Mathiesen B V and Leahy M 2010 A review of computer tools for analysing the integration of renewable energy into various energy systems Applied energy 
87(4) 1059-1082

[20] Sirikum J, Techanitisawad A and Kachitvichyanukul V 2007 A new efficient GA-benders' decompositionmethod: for power generation expansion planning with emission controls IEEE Trans Power Syst 22(3) 1092-1100

[21] Kazempour S J, Conejo A J and Ruiz C 2011 Strategic generation investment using a complementarity approach IEEE Trans Power Syst 26(2) 940-948

[22] Rajesh K, Kannan S, Thangaraj C 2016 Least cost generation expansion planning with wind power plant incorporating emission using differential evolution algorithm Int J Electr Power Energy Syst 80 275-286

[23] Masud A S and Yildirim M B 2012 Three multiple criteria models for power generation expansion planning: A review Manuf Eng 1(1) 1146-1151

[24] Bylling H C, Pineda S and Boomsma T K 2018 The impact of short-term variability and uncertainty on long-term power planning Annals of Operations Research 1-25

[25] Jones L E 2017 Renewable energy integration: practical management of variability uncertainty and flexibility in power grids Academic Press

[26] Oree V Hassen S Z S and Fleming P J 2017 Generation expansion planning optimisation with renewable energy integration: A review Renewable and Sustainable Energy Reviews 69 790803

[27] Senatla M and Bansal R C 2018 Review of planning methodologies used for determination of optimal generation capacity mix: the cases of high shares of PV and wind IET Renewable Power Generation 12(11) 1222-1233

[28] Welsch M, Howells M, Hesamzadeh M R Ó, Gallachóir B et. al 2015 Supporting security and adequacy in future energy systems: The need to enhance long-term energy system models to better treat issues related to variability International Journal of Energy Research 39(3) 377 396

[29] Poncelet K, Delarue E, Duerinck J, Six D and D'haeseleer W 2014 The importance of integrating the variability of renewables in long-term energy planning models In BAEE Research

[30] Després J, Hadjsaid N, Criqui P and Noirot I 2015 Modelling the impacts of variable renewable sources on the power sector: Reconsidering the typology of energy modelling tools Energy 80 486-495

[31] Bessa R, Moreira C, Silva B and Matos M 2014 Handling renewable energy variability and uncertainty in power systems operation Wiley Interdisciplinary Reviews: Energy and Environment 3(2) 156-178

[32] Vithayasrichareon P, Riesz J and MacGill I 2017 Operational flexibility of future generation portfolios with high renewables Applied energy 206 32-41

[33] Moreira A, Pozo D, Street A and Sauma E 2017 Reliable renewable generation and transmission expansion planning: Co-optimizing system's resources for meeting renewable targets IEEE Trans Power Syst 32(4) 3246-3257

[34] Akinbulire T O, Oluseyi P O and Babatunde O M 2014 Techno-economic and environmental evaluation of demand side management techniques for rural electrification in ibadan nigeria Int J Energy Environ Eng 5(4) 375-385

[35] Denholm P and Hand M 2011 Grid flexibility and storage required to achieve very high penetration of variable renewable electricity Energy Policy 39(3) 1817-1830

[36] Castillo A and Gayme D F 2014 Grid-scale energy storage applications in renewable energy integration: A survey Energy Conversion and Management 87 885-894

[37] Ding J and Somani A 2010 April A long-term investment planning model for mixed energy infrastructure integrated with renewable energy In 2010 IEEE Green Technologies Conference pp 1-10

[38] Li S, Coit D W and Felder F 2016 Stochastic optimization for electric power generation expansion planning with discrete climate change scenarios Electric Power Syst Res 140 401412

[39] Farghal S A and Aziz M A 1988 Generation expansion planning including the renewable energy 
sources IEEE Transactions on Power Systems 3(3) 816-822

[40] Hu Z, Jewell W T 2013 Optimal generation expansion planning with integration of variable renewables and bulk energy storage systems In: 2013 1st IEEE Conference on Technologies for Sustainability (SusTech) pp 1-8

[41] Aghaei J, Akbari M, Roosta A, Gitizadeh M and Niknam T 2012 Integrated renewableconventional generation expansion planning using multiobjective framework IET Gener Transm Distrib 6(8) 773-784

[42] Pina A, Silva C A and Ferrão P 2013 High-resolution modeling framework for planning electricity systems with high penetration of renewables Applied Energy 112 215-223

[43] Conejo A J, Carrion M and Morales J M 2010 Decision Making Under Uncertainty in Electricity Markets Springer

[44] Powell W 2014 Energy and Uncertainty: Models and Algorithms for Complex Energy Systems AI Magazine 35(3) 8-21

[45] Powell W B 2019 A unified framework for stochastic optimization European Journal of Operational Research 275(3) 795-821

[46] Soroudi A and Amraee T 2013 Decision making under uncertainty in energy systems: State of the art Renewable and Sustainable Energy Reviews 28 376-384

[47] Powell W B and Meisel S 2015 Tutorial on stochastic optimization in energy - Part I: Modeling and policies IEEE Transactions on Power Systems 31(2) 1459-1467

[48] Khazaei J and Powell W B 2015 SMART-Invest: a stochastic dynamic planning for optimizing investments in wind solar and storage in the presence of fossil fuels. The case of the PJM electricity market Energy Systems 1-27

[49] Meisel S and Powell W B 2017 Dynamic decision making in energy systems with storage and renewable energy sources In Advances Energy System Optimization 87-101

[50] Meza J L C, Yildirim M B and Masud A S 2007 A model for the multiperiod multiobjective power generation expansion problem IEEE Trans Power Syst 22(2) 871-878

[51] Tekiner H, Coit D W and Felder F 2010 A Multi-period multi-objective electricity generation expansion planning problem with Monte-Carlo simulation Electr. Pow. Syst. Res. 80(12) 1394-1405

[52] Kies A, Schyska B, Viet D T, Heinemann L B D and Schramm S 2017 Large-Scale Integration of Renewable Power Sources into the Vietnamese Power System Energy Procedia 125207 213

[53] Noorollahi E, Fadai D, Ghodsipour S H and Shirazi M A 2017 Developing a new optimization framework for power generation expansion planning with the inclusion of renewable energy - A case study of Iran J. Renew Sustain Energy 9(1)

[54] Feoktistov A, Gorsky S, Sidorov I, Kostromin R, Edelev A and Massel L 2019 Orlando Tools: Energy Research Application Development through Convergence of Grid and Cloud Computing 4th Russian Supercomputing Days 2018. CCIS 965 pp 289-300

[55] http://hpc.icc.ru 